\title{
An Experimental Study in the Surgical and Anesthesio- Pharmacological Implications of the Practical Applicability of the Concept of Myoplastic Transposition Through a Forearm Fascia Breach
}

\begin{abstract}
MARK-EDWARD POGARASTEANU1,2*, RUXANDRA COSTEA ${ }^{3}$, AHMED BERAMI ${ }^{4}$, ELENA DRIGNEI ${ }^{4}$, MARIUS MOGA ${ }^{1}$, STEFANIA MARIANA RAITA ${ }^{3}$, ROSALIE ADINA BALACEANU ${ }^{3}$, IULIANA IONASCU ${ }^{3}$, RALUCA BARBILIAN ${ }^{5}$, FLORENTINA IONITA RADU ${ }^{1}$

${ }^{1}$ Carol Davila Central Universitary Emergency Military Hospital, 134 Calea Plevnei Str., 010825, Bucharest, Romania

${ }^{2}$ Carol Davila University of Medicine and Pharmacy Bucharest, 3-7 Dionisie Lupu Str., 020022, Bucharest, Romania

3University of Agronomic Sciences and Veterinary medicine of Bucharest, 59 Marasti Blvd., 011464, Bucharest, Romania

${ }^{4}$ Abbeville Hospital Center, Abbeville, 43 Rue de L'Isle, France

${ }^{5}$ ATI Department, Colentina Clinical Hospital, 19-21 Stefan cel Mare Blvd., 020125, Bucharest, Romania

The traumatic or surgical amputation of the forearm or of the hand is a challenging interdisciplinary domain, requiring the collaboration of surgeons, engineers, prostheticians, clinical pharmacology experts in chronic pain management, exoprosthesis manufacturing companies, social workers and last but not least the patient himself/herself. There are a relative few methods of surgical preparation of the amputation stump for use use an external prosthesis. Most of these techniques do not provide a sufficient number of electrical SEMG signals for the efficient control of a modern myoelectric exoprosthesis. We present the surgical aspects and anesthesio-pharmacological implications of the practical study into the applicability of the concept of myoplastic transposition through a forearm fascia breach. We present the data and we discuss the results of SEMG signal acquisition, both before and after the procedure, and we conclude regarding the potential of the method as a means of improving the current standard surgical technique.
\end{abstract}

Keywords: myoprosthesis, forearm amputation, anaesthesia, myoplastic transposition, surface electromyography.

The use of prosthesis to supplement the function of an amputated limb is a practical problem that has captivated the imagination of mankind from the earliest times in recorded history [23], up until today, continually adapting to the technological and medical evolution of humanity. Though both functionally and cosmetically the external prosthesis for thoracic or pelvic limb loss are far from replacing the original limb, advancing technologies have allowed to come ever closer to this goal. [2]. The patient that has suffered an amputation may expect to regain a significant part of his or her lost functionality and independence [9].

The forearm myoprosthesis is a type of exoprosthesis that is based on receiving myoelectric signals from the surface of the skin on the amputation stump [6] and transmitting the motor command to the effector part of the prosthesis [13]. The way in which myoelectrical prosthesis work is based on collecting and measuring myoelectrical signals from the amputation stump [22]. Following an amputation procedure there are muscles remaining on the amputation stump that are not attached distally to an articulated segment and cannot perform an action, [17] but they still receive motor commands and perform contractions, an action that will remain without a motor effect, but will nonetheless generate an electrical activity. This activity is received by sensors (electrodes) [4] and is used to command an action of the myoprosthesis [12]. The electrodes, also called myoelectrodes [1], can be of the surface kind (applied on the skin) [19] or intramuscular (surgically implanted in the muscle) [21]. Most often surface electrodes are used, as they are easier to apply and to use, although the intramuscular types offer a signal that is superior both in clarity as well as in definition [5].

*email: mark.pogarasteanu@gmail.com
The amputation may be performed through one of the classic techniques, [3] that allows for the retraction of the sectioned muscles and tendons into permanent random modified positions or sees that opposing muscle groups are anchored to each other over the radius and ulna in an inordinate fashion [20], or through the CONM method (circumferential osteoneuromioplasty), [16] involving the surgical attachment of the muscular ends and of the tendons transosseous to the radius and the ulna, in anatomic positions (or as close as possible), thus maintaining their position and facilitating the collection of sEMG signals [24].

Electromiography (EMG) [10] is a medical procedure that allows for the electrical signals emitted by the skeletal muscles to be recorded and, in our case, later used in the control of a myoelectric prosthesis. The level at which the EMG signals are measured is important, as only superficial muscles may be measured, the signal from the deep ones becoming blurred from the overlapping with the signal of the superficial ones. Also, the thickness of the adipose layer that is interposed between the muscles and the SEMG sensor directly and proportionally decreases the intensity of the signal [18].

By analyzing the classical and the CONM amputation techniques, as well as the principles of surface EMG signal acquisition, we have synthesized a series of concepts:

-the main biological material that shields the electrical impulse from the source (the muscle tissue) to the surface electrode is the adipose tissue [18];

-one of the principles behind the CONM technique is the transposition of the median, radial and ulnar nerves, as well as the partial resection of the fascia, which constitute an important progress, which can be taken even further by completely eliminating the insulating layer of tissue; 
-the complete resection of the subcutaneous adipose layer is not practical, both for surgical reasons, as it would compromise the vascular supply of the skin, as well as for reasons regarding the amputation stump, as eliminating the adipose layer would make fitting the prosthesis difficult through the direct compression of the prosthesis sleeve on the stump, without any form of dampening.

So, in order to improve the myoelectric signal that that is being received from the amputation stump, we propose the surgical concept of myoplastic transposition through fascial breach that aims to overcome the inconveniences of the electric insulation of the forearm muscles by the fascia and the subcutaneous adipose layer by the transposition of each individual muscle transfascially and trans-subcutaneously, with a wide reinsertion underneath the dermis, conceptually this surgical procedure leading to a minimalization of the electrical resistance in the path of the signal from the muscle to the skin sensor.

We decided to test the surgical procedure using an animal model, the domestic rabbit, Oryctolagus cuniculus, due to the major resemblances between the forearm and hand regions of this species and those of the human species, as well as due to practical convenience $[15,26]$. The comparative anatomy of Homo sapiens and of Oryctolagus cuniculus, regarding the forearm and hand regions, are very similar in regards to osteology, myology, vascularisation and innervation, so much so that the animal model may be used as an experimental basis and conclusions may be drawn from the experiment $[8,11,25]$

\section{Experimental part}

\section{Study objective and hypothesis}

The main objective of this study is to test the practical applicability of the principle that is the basis of the fascial breach myoplastic surgical procedure. The secondary objective is to evaluate the influence that the application of this method has on the amplitude of the electrical signal generated by the muscle activity in the area where we intervene surgically.

The main hypothesis is that the method of myoplastic transposition through fascial breach is feasible, easy to perform and reproducible. The secondary hypothesis is that the practical application of this method leads to an increase in the amplitude of signals that are muscularly generated and superficially received at the level of the epidermis.

\section{Materials and methods}

The materials needed to perform the study included: 5 individual domestic rabbits Oryctolagus cuniculus, aged between 3 and 6 months, M:F=1:4, Hantek Oscilloscope dso-2090 usb, a laptop with the Hantek DSO-2090 USB oscilloscope software, TENS MA LTM710-711 cutaneous electrostimulator, Pajunk Nerve Stimulator MultiStim Sensor transcutaneous stimulator, standard surgical equippement, unresorbable 3/0 surgical suture, anaesthesic materials, cages for housing the study subjects and standardized rabbit food.

Selection criteria for the test subjects:

-inclusion criteria: domestic rabbits, ages 3 to 6 months, weighing between 1500 and 3000 grams, all from the same source.

-exclusion criteria: the presence of a known or visible pathology or a lethargic response to external stimuli.

In order to test the hypothesis and accomplish the objectives we decided to perform an experimental study, in collaboration with the Physiology, Compared Anatomy, Surgery and Anaesthesiology Departments from the University of Agronomical Sciences and Veterinary Medicine of Bucharest, Romania.
The principles for selecting the test subjects, their housing and feeding, asepsis and antisepsis during the surgical procedures, as well as the surgical principles (excluding the method for fascial breach muscle transposition), as well as the code of conduct before, during and after the intervention, were in accordance with the generally accepted methodology and in accordance with the Directive 2010/63/EU on the protection of animals used for scientific purposes [14,26].

All five test subjects were clinically examined (general evaluation, body condition, weighing) and it was determined that the entire group was class I anesthetic risk, according to the ASA Classification, adapted for veterinary medicine (table 1) [7].

Table 1

PREANESTHETIC EXAMINATION

\begin{tabular}{|c|c|c|c|c|}
\hline \multicolumn{2}{|c|}{ Subject } & $\begin{array}{c}\text { Weight } \\
\text { (kg) }\end{array}$ & $\begin{array}{c}\text { Age } \\
\text { (months) }\end{array}$ & $\begin{array}{c}\text { ASA } \\
\text { Status }\end{array}$ \\
\hline 1 & $\mathrm{M}$ & 2.8 & 6 & ASA I \\
\hline 2 & $\mathrm{M}$ & 1.8 & 3 & ASA I \\
\hline 3 & $\mathrm{~F}$ & 2.2 & 4 & ASA I \\
\hline 4 & $\mathrm{M}$ & 1.7 & 3 & ASA I \\
\hline 5 & $\mathrm{M}$ & 2.48 & 5 & ASA I \\
\hline
\end{tabular}

Preparing the test subjects has involved a period of preoperative adjustment in order to minimise the levels of stress hormones ( 72 hours). The contention of the test subjects was done carefully, reducing the factors of stress to a minimum. Venous acces was obtained at the suricular vein. The medication was administered subcutaneous, intramuscular and intravenous. Choosing the anaesthesia protocols kept into account the particularities of the species and the associated anaesthesic risks [7]. The premedication can influence the anaesthesia protocol by significantly reducing the necesary doses for induction and maintenence. Anticolinergics are not routinely used, only in situations that impose their use (bradicardia) glicopirolate is recomended $(0.1 \mathrm{mg} / \mathrm{kg})$, as atropine is inactivated by a specific enzime (atropinestherase) [7].

Premedication and anaesthesia induction were done by injection and before this the test subjects were preoxygenated $1-2$ minuts with $100 \%$ oxygen. The anaesthetic doses were: Midazolam $2 \mathrm{mg} / \mathrm{kg}$ and Ketamine $50 \mathrm{mg} / \mathrm{kg}$, administered intramuscular [7]. After inducing anesthesia (fig. 1), the targeted area (the left thoracic limb, shoulder, arm and forearm) was prepared. The maintenance of the anesthesia was done by supplementing the doses of Midazolam (bolus in the range of $2-3.57 \mathrm{mg} / \mathrm{kg}$ ) and Ketamine $(50-53.57 \mathrm{mg} / \mathrm{kg})$. Ketamine does not produce an important respiratory depression, and the breathing reflexes are maintained [7]. These reactions may be reduced through the use of benzodiazepines (midazolam, diazepam). The doses used for each test subject can be found in table 2 [7].

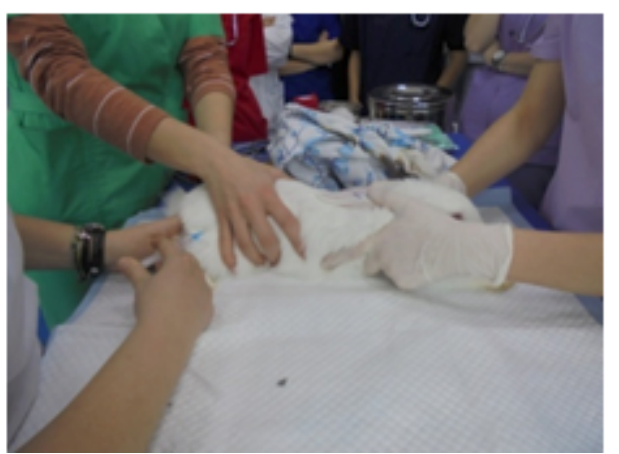

Fig. 1. Intramuscular anesthesia. This image is from the author's database. 
Table 2

DOSES OF ANESTHETICS

\begin{tabular}{|c|c|c|c|}
\hline Subject & \multirow{2}{*}{$\begin{array}{c}\text { Weight } \\
\text { (kg) }\end{array}$} & & \multicolumn{2}{|c|}{ Supplement } \\
\cline { 3 - 4 } & & $\begin{array}{c}\text { Ketamine } \\
\text { (mg/kg) }\end{array}$ & $\begin{array}{c}\text { Midazolam } \\
\text { (mg/kg) }\end{array}$ \\
\hline $\mathbf{l}$ & 2.8 & 53.57 & 3.57 \\
\hline $\mathbf{2}$ & 1.8 & 50 & 2 \\
\hline $\mathbf{3}$ & 2.2 & - & - \\
\hline $\mathbf{4}$ & 1.7 & - & - \\
\hline $\mathbf{5}$ & 2.48 & - & - \\
\hline
\end{tabular}

The anesthesia was continuously monitored, evaluating its depth and the subject's reflexes (tested at the digital, auricular and palpebral levels), modifications in the respiratory frequency, in the cardiac frequency, the color of the mucosa, the capillary filling time and the body temperature. During the waking period the monitoring was continued and heating was ensured, by positioning on an electric blanket. Feeding was resumed gradually, at 1-2 hours postoperative. For analgesia $0.4 \mathrm{mg} / \mathrm{kg}$ of meloxicam were administered i.m. for 3 consecutive days. The antibiotherapy was continued for 3 days postoperative (amoxicillin $15 \mathrm{mg} / \mathrm{kg}$ ) [7]. After anesthesia was achieved and the limb that was to be operated was prepared, the test subject was connected to a heart monitor for the duration of the procedure.

The first stage was to apply a $72 \%$ alcohol solution in order to facilitate the transmission of electric impulses; it is noted that even after trimming the selected area, the remaining hair was in a significant quantity.

We started by measuring the amplitude of the electrical signals that were transmitted to the skin in the preestablished areas with the oscilloscope (the skin areas that correspond to the flexor carpi ulnaris and flexor profundis digitorum muscles). We noted the results for the flexor carpi ulnaris and flexorprofundis digitorum muscles. We continued by electrostimulating transcutaneously the left brachial plexus using the Pajunk Nerve Stimulator MultiStim Sensor ( $15 \mathrm{~mA}, 1 \mathrm{~Hz}$ ), (figs. 2 and 3) and we remeasured the amplitude of the electrical signals that were transmitted to the skin with the oscilloscope.
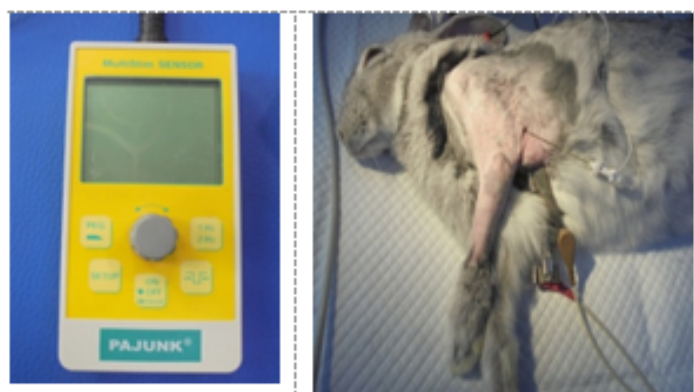

Figs. 2-3: The Pajunk Nerve Stimulator MultiStim Sensor (2) and the electrode used to directly stimulate the brachial plexus (3). These images are from the author's database.

We noted the results for the flexor carpi ulnaris and flexor profundis digitorum muscles.

Preoperatively we prepared the skin area by marking the incision site (the skin area that corresponds to the middle of the flexor carpi ulnaris muscle), we applied local antiseptics (betadine) and we draped the area in a sterile fashion (fig. 4).

We incised the skin $1 \mathrm{~cm}$ at the marked level. We dissected the subcutaneous tissue, and then dissociated it with a Pean clamp, in order to prepare the receiving area. We incised the fascia $1.5 \mathrm{~cm}$ and we dissected the

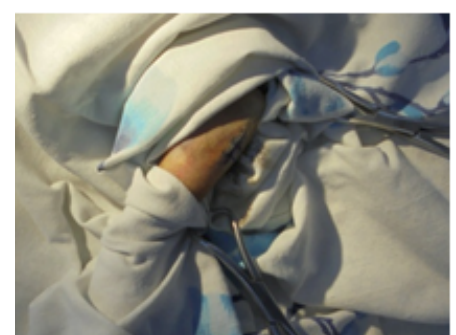

Fig. 4. Draping with Betadine and isolating with sterile drapes. This image is from the author's database

subfascial plane. We localized the medial portion of the flexor carpi ulnaris muscle and we mobilized it (fig. 5).

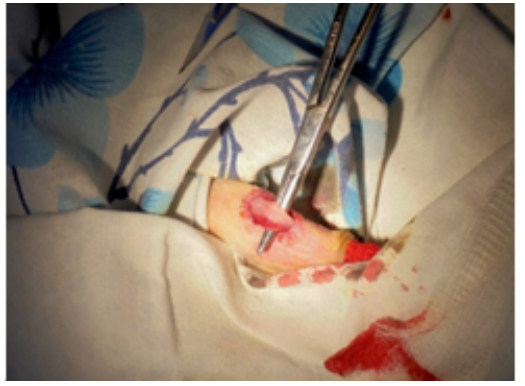

Fig. 5. The fascia is incised, the subfascial plane is dissected and the medial portion of the flexor carpi ulnaris muscle is mobilized. This image is from the author's database.

We gently pulled the muscle from the distal towards the proximal with a Pean clamp in order to reduce the crushing of the muscle to a minimum and we sectioned the muscle transversely (fig. 6). The distal muscle end was left to freely retract.

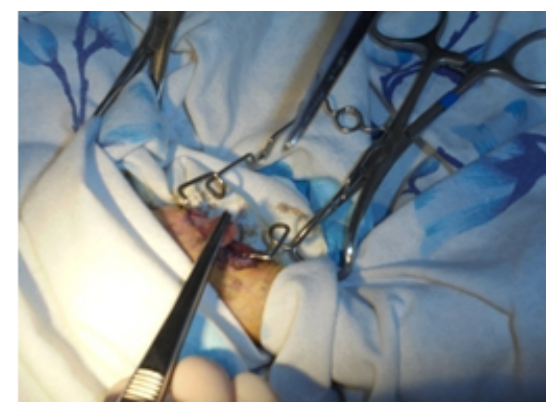

Fig.6. Traction and transverse muscle sectioning. This image is from the author's database

We sutured the proximal free end of the sectioned muscle in a $Z$ fashion using a 3.0 non-resorbable suture and using gentle traction we passed the muscle through the fascia, anchoring it to the subcutaneous tissue (fig. 7). The fascial breach was left unsutured.

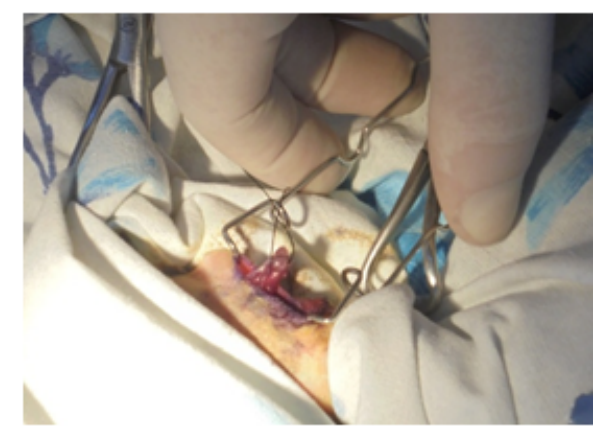

Fig.7. The free end of the muscle is sutured, and then anchored subcutaneously. This image is from the author's database 
The skin was closed in a single layer fashion using a 3.0 non-resorbable suture. Postoperative we tested the amplitude of the electric signal generated by the muscles at the same skin site as was done preoperative, both for the flexor carpi ulnaris muscle as well as the flexor profundis digitorum muscle (fig. 8).

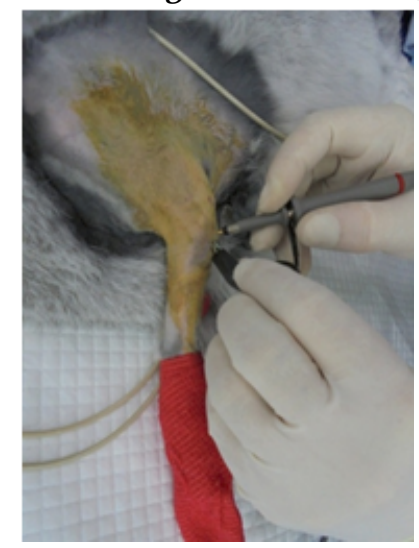

Fig.8. Postoperative testing. This image is from the author's database.

We dressed the wound and administered postoperative antibiotics for 3 days. The sutures were removed at 10 days postoperative. We monitored the test subjects closely during the postoperative period.

\section{Control}

The control was accomplished by testing in a similar method, before and after the surgical intervention, an area of skin adjacent at the level of the left forearm of the test subjects, corresponding to the flexor profundis digitorum muscle, that was not subjected to the surgical intervention.

\section{Results and discussions}

We performed the measurements setting the oscilloscope for signal reception on the channel $\mathrm{CH} 1,200$ $\mathrm{mV}$ values, 20.0 us, and we obtained a set of values that was noted for statistical interpretation. In order to interpret the data, we accepted a minimum of 10 periods whose values were noted, retaining the maximum amplitude (the cumulated value between the highest positive and lowest negative peaks +/- within a period). In order to show the differences between the visual aspects of the waves, we present in figures 9 to 11 photographic recordings from the experiments that we consider relevant.

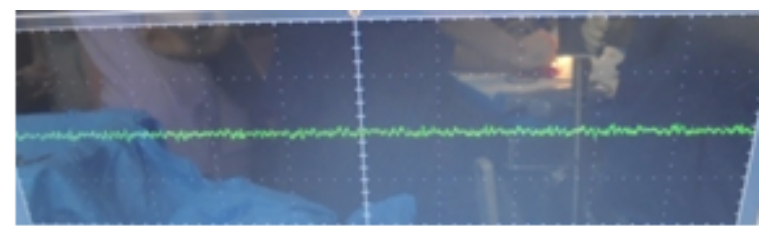

Fig.9. The graphic aspect of the wave while testing for background activity in the skin area that corresponds to the flexor carpi ulnaris muscle (image from the author's database)

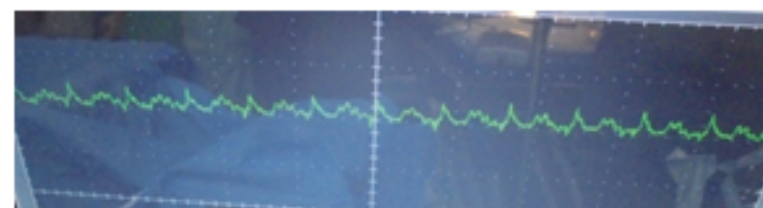

Fig.10. The graphic aspect of the wave while using the MultiStim Sensor Pajunk nerve stimulator, in the skin area that corresponds to the flexor carpi ulnaris muscle (image from the author's database)

Figure 12 shows the average amplitude values for the signal received by the oscillograph as well as their graphical representation, in regards to the preoperative testing.

Figure 13 shows the average amplitude values for the signal received by the oscillograph as well as their graphical

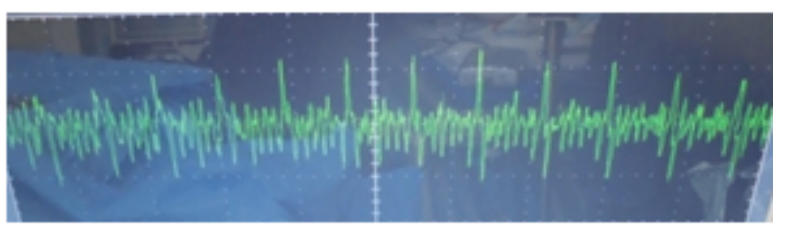

Fig.11. The graphic aspect of the wave while testing postoperative for activity in the skin area that corresponds to the flexor carpi ulnaris muscle (image from the author's database).

\section{Amplitude (preoperative testing)}

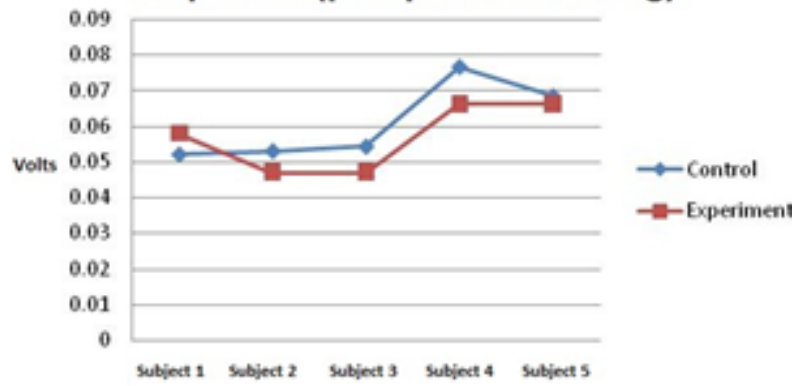

Fig.12. Graphical representation of the average amplitude values for the preoperative tests

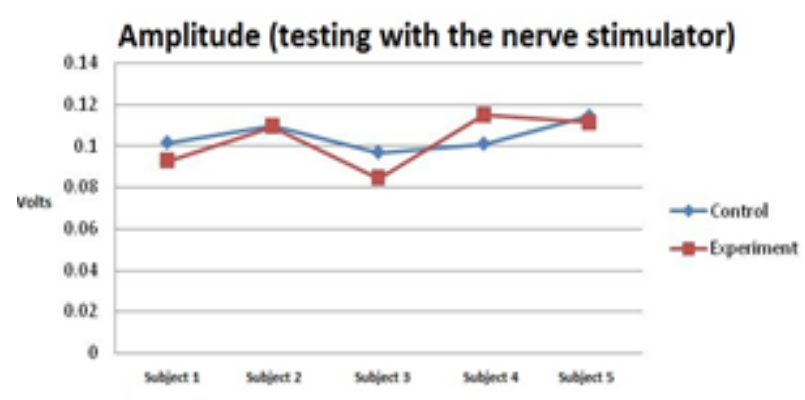

Fig.13. Graphical representation of the average amplitude values for the tests involving the Pajunk brachial plexus stimulator

representation, in regards to the tests involving the Pajunk brachial plexus stimulator.

Figure 14 shows the average amplitude values for the signal received by the oscillograph as well as their graphical representation, in regards to the postoperative testing.

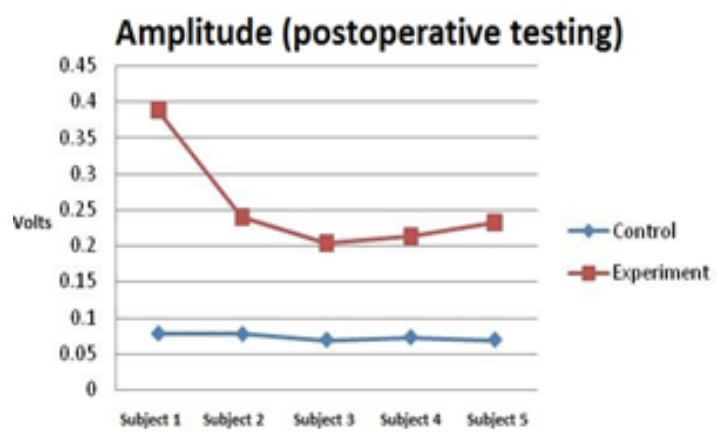

Fig. 14. Graphical representation of the average amplitude values for the postoperative tests

Figures 15 and 16 show the graphical representations of the average amplitude values of the signal received by the oscillographe during the tests for the control and experiment groups.

By analyzing the results of the experimental study we establish two types of information: a set of quantifiable data and a series of empirical finds that we will also explore. We aim to summarily analyze the results from the perspective offered by the set of data regarding the intensity of the signal and not an detailed analysis of the characteristics of the waves, as this would surpass the 


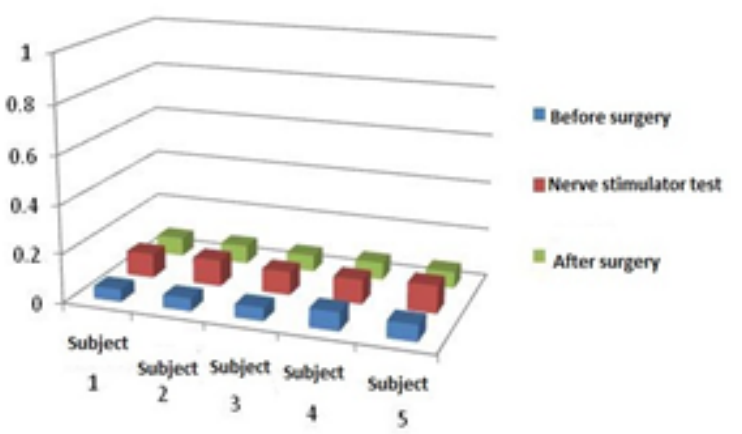

Fig.15. Graphical representation of the average amplitude values for the control group.

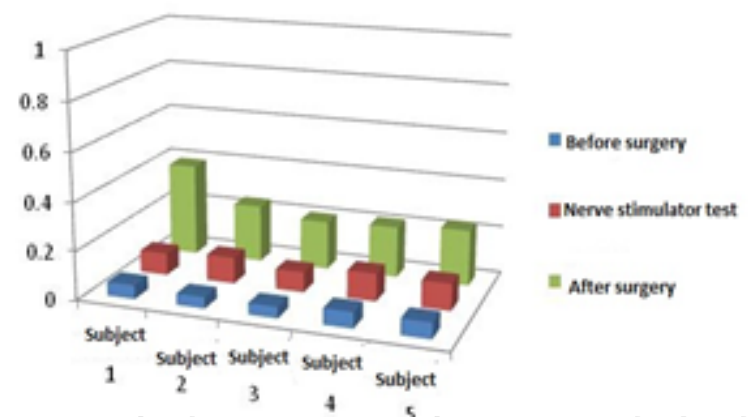

Fig.16. Graphical representation of the average amplitude values for the experiment group.

aim of this paper, and also our expertise. The proposed surgical procedure aims to increase the amplitude of the signals received at skin level and our purpose is to determine the effectiveness of the method in modifying that signal, not to analyze and characterize technically the signals that we obtain. Regarding the acquiring of the signals, we eliminated the acquisition errors and the inconclusive signals, and we repeated the test for each subject until we obtained clear, quantifiable and stabile signals.

The average amplitude of the signal transmitted at skin level and received by the oscillographe has had relatively close values for each subject regarding preoperative testing, both for the skin area that corresponds to the flexor profundis digitorum muscle (the control signal), as well as for the skin area that corresponds to the flexor carpi ulnaris muscle (the studied signal). In both cases, the average overall values were between a minimum of $0.051 \mathrm{mV}$ and a maximum of $0.068 \mathrm{mV}$ for the control group, and a minimum of $0.046 \mathrm{mV}$ and a maximum of $0.066 \mathrm{mV}$ for the studied group. For all five subjects the values were close in range, without a relevant difference between the control skin area and the skin area corresponding to the operated muscle.

Aiming to discern whether the values we obtained during the first test represent an activity mostly influenced by musculature, and as we could not simply ask the test subjects to perform a certain action on command, in order to evaluate voluntary movement, we performed a test by stimulating the brachial plexus using the Pajunk stimulator. The average values we obtained for the control group were between $0.094 \mathrm{mV}$ and $0.114 \mathrm{mV}$ and for the study group were between $0.084 \mathrm{mV}$ and $0.114 \mathrm{mV}$. For the five subjects the values were close, with no notable differences between the control skin areas and the skin areas on which we later on intervened surgically.

After performing the myoplastic transposition through forearm fascial breach we tested again using the oscilloscope, and for the control group the values varied between a minimum of $0.068 \mathrm{mV}$ and a maximum of
$0.077 \mathrm{mV}$, while for the study group the values we obtained varied between $0.203 \mathrm{mV}$ and $0.388 \mathrm{mV}$. Overall, the values obtained after performing the myoplastic transposition through forearm fascial breach in the study area were significantly higher compared to those from the control area, for the latter the values being close to those obtained during the preoperative tests.

We consider that certain aspects regarding the practical nature of the experiment need to be also discussed. We chose to use an oscilloscope as an instrument of measurement instead of an electromyograph due to the fact that the commercially accessible electrodes for an electromyograph have a large contact area, being unsuitable for the forearm of Oryctolagus cuniculus, if any reasonable degree of fine measuments were to be expected.

Regarding anesthesia, we found a decrease in the need for supplementing the anesthetics and respectively a decrease in the time needed to perform the surgical procedure; we believe this to be an indicator of a steep learning curve. The surgical technique is easy to perform once the basic surgical concept is assimilated: the body of the targeted muscle is brought as close to the skin as possible as affixed there, thus bypassing the fascial al adipose layers.

Being an experimental study based on an animal model, the results are not completely indicative of whatperforming the procedure on a human subjectmightyield. We consider that in the case of human subjects, the results have the potential of being superior, as the adipose layer is minimal in the forearm of the Oryctolagus cuniculus, while the human forearm has a significantly greater adipose layer.

We consider that the study has verified the hypothesis and has reached the established objectives.

The experimental work and clinical results obtained recommend further research in some interdisciplinary areas [27-34].

\section{Conclusions}

After performing the experimental study we draw a series of conclusions:

The myoplastic transposition through fascial breach is a surgical procedure that leads to an increase in the postoperative amplitude of the myoelectric signals that are being received at skin level. The procedure is easy to perform, conceptually simple and with a steep learning curve, posing little anesthesical challenges in itself.

The amplitude of the myoelectric signal is directly influenced by the distance that it must travel from the emitter (the muscle) to the receiver (the surface electrode) and also by the nature of the tissues that are interposed between the two.

The myoplastic transposition through fascial breach may be performed for each muscle that can be individualized at the level of the forearm, thus offering the possibility of using over 15 areas of control, where the received myoelectric signal can control a function of the myoprosthesis that can pe equipped with a greater number of functions than those available today. We foresee the possibility of creating a myoprosthesis that would have all of the important biomechanical functions of the forearm and hand, as an importantstep in the potential development of exoprothesis producing technical procedures.

\section{References}

1.AL-TIMEMY A, A preliminary investigation of the effect of force variation for myoelectric control of hand prosthesis. Osaka : Conf Proc IEEE Eng Med Biol Soc. 2013; 5758-5761. 
2.BELTER JT, SEGIL J, DOLLAR A, WEIR R, Mechanical design and performance specifications of anthropomorphic prosthetic hands: $A$ review. J Rehabil Res Dev., 2013; 50(5):599-618.

3.CANALE ST, Campbell's Operative Orthopaedics 11th Edition. Mosby Elsevier, 2008.

4.CIPRIANI C, ANTFOLK C, CONTROZZI M, LUNDBORG G, ROSEN B, CARROZZA MC, SEBELIUSF, Online myoelectric control of a dexterous hand prosthesis by transradial amputees. IEEE Transactions on Neural Systems and Rehabilitation Engineering, 2011; 19(3): 260-270.

5.CIPRIANI C, SEGIL J, BIRDWELL A, WEIR R, Dexterous Control of a Prosthetic Hand Using Fine W ire Intramuscular Electrodes in Targeted Extrinsic Muscles. IEEE Trans Neural SystRehabil Eng. 2014; 22(4):828836.

6.CORDELLA F, CIANCIO A, SACCHETTI R, DAVALLI A, CUTTI A, GUGLIELMELLI E, ZOLLO L, Literature Review on Needs of Upper Limb Prosthesis Users. Front Neurosci., 2016; 10:209.

7.COSTEA R., POGARASTEANU M. E., Evaluation of the Anesthesia Protocol for Controlled Myoplastic Transposition in Oryctolagus Cuniculus. Agriculture for Life, Life for Agriculture Conference Proceedings, Sciendo, 2018; 1(1): 438-439.

8.CRABB ED, Principles of funcpional anatomy of the rabbit. Philadelphia, P. Blakiston's son \& C0., 1931; p. 54-60, 70-81.

9.CUTTI A, PAREL I, LUCHETTI M, GRUPPIONI E, ROSSI N, VERNI G, The Psychosocial and Biomechanical Assessment of Amputees Fitted with Commercial Multi-grip Prosthetic Hands. Bentham Science Publishers, 2012; ISBN: 978-1-60805-438-1.

10.DALEY H, ENGLEHART K, HARGROVE L, KURUGANTI U, High density electromyography data of normally limbed and transradial amputee subjects for multifunction prosthetic control. J Electromyogr Kinesiol., 2012; 22(3):478-484.

11.DYCE KM, WENSING CJ G, Textbook of veterinary anatomy. Saunders Elsevier, 2010; p. 70-98.

12. HAHNE J, FARINA D, J IANG N, LIEBETANZD, A Novel Percutaneous Electrode Implant for Improving Robustness in Advanced Myoelectric Control. Front Neurosci., 2016; 10:114.

13.HAMDI N, DWEIRI Y, AL-ABDALLAT Y, HANEYA T, A practical and feasible control system for bifunctional myoelectric hand prostheses. Prosthet Orthot Int., 2010; 34(2):195-205.

14.HARCOURT-BROWN F, Textbook of rabbit medicine. Reed Elsevier, 2002; ISBN: 9780702038136.

15.HORNE CRAIGIE E, Bensley's Practical Anatomy Of The Rabbit. Philadelphia:The Blakiston Company, 1948; p. 60-71, 109-117.

16.***http://drks-neu.uniklinik-freiburg.de/drks_web/ navigate.do?navigationld=trial.HTML\&TRIAL_ID=DRKS00004868. [Online]

17.J AEGERSSM, ARENDZEN JH, DEJONGH HJ , Changes in hip muscles after above-knee amputation. Clin Orthop Relat Res., 1995; (319):27684.

18.KUIKEN T, LOWERY M, STOYKOV N, The effect of subcutaneous fat on myoelectric signal amplitude and cross-talk. Prosthet Orthot Int., 2003; 27(1):48-54.

19.LAZARO J, ABUAN D, LINSANGAN N, PANGANIBAN A, Surface Electromyography Signal for Control of Myoelectric Prosthesis of the Upper-Limb Using Independent Component Analysis. Jounal of Automation and Control Engineering, 2014; 2(1):94-98.
20.MASMEJ EAN E, OUAKNINE M, VALENTI P, CAMILLERI A, CHIESA G, Amputations et désarticulations des membres. Elsevier Encycl Med Chir (Editions Scientifiques et Medicales Elsevier SAS), Paris, 2000. 21.MERRILL DR, LOCKHART J, TROYK PR, WEIR RF, HANKIN DL, Development of an implantable myoelectric sensor for advanced prosthesis control. Artif Organs., 2011; 35(3):249-252.

22.SANG Y, LI X, LUO Y, Biomechanical design considerations for transradial prosthetic interface: A review. Proc Inst Mech Eng $\mathrm{H}$., 2016; 230(3):239-50.

23.SELINCOURT A,. Herodotus, the Histories. New York Penguin Books, 1954.

24.SPIRES M, KELLY B, DAVIS A, Prosthetic Restoration and Rehabilitation of The Upper and Lower Extremity. Demos Medical, 2014; ISBN: 978-1-936287-66-6.

25.STURTZ R, ASPREA L, Anatomy and Physiology for veterinary technitians and nurses. Wiley-Blackwell, 2012; p. 10-40; 48-50.

26.TOBIAS K, JOHNSTON S, Veterinary Surgery: Small Animals. Saunders Elsevier, 2012; 2:760, 785-788. ISBN: 978-1-4377-0746-5.

27.OLTU, O., VOICULESCU, V., POPESCU, V., DASCALU, M., BARBILIAN, A., Advanced power monitoring of an ARM processor, Computational Engineering In Systems Applications, Book Series: Mathematics and Computers in Science and Engineering, 2008, p. 243-246, WOS:000260490500031.

28.FRANTI, D. TUFIS, S. GOSCHIN, M. DASCALU, P. L. MILEA, G. STEFAN, T. BALAN, C. SLAV, R. DEMCO, Virtual environment for robots interfaces design and testing, CAS 2005, International Semiconductor Conference; IEEE; volume 1-2, pp. 463-466; 2005; WOS: 000237180300103.

29.S. OSICEANU, M. DASCALU, E. FRANTI, A. BARBILIAN, Intelligent Interfaces for Locomotory Prosthesis; IJ CNN: 2009 International Joint Conference on Neural Networks, Vol1-6; IEEE; IEEE International Conferences on Neural Networks (IJCNN); Pages: 1933-1938; 2009; WOS: 000280591601024. Atlanta, J une 14-J une 19, 2009, USA

30.DASCALU, M., Cellular Automata Hardware Implementations - an Overview, in Romanian Journal of Information Science and Technology, Volume 19, Number 4, 2016, pp. 360-368, WOS:000405151700005.

31.GOSCHIN S., FRANTI E., DASCALU M., PIETRAROIU M., Autonomous agents with control systems based on genetic algorithms, in Proceedings of the 12th IASTED International Conference on Robotics and Applications, Book Series: IASTED International Conference on Robotics and Applications, pp 49-54, 2006

32. NITA, D; GURZUN, M; CHIRIAC, L; CIRSTEA, Al; PAREPA, RI; BARBILIAN, AG; Impact of stent diameter and length on in-stent restenosis after bare metal stent implantation, Romanian Biotechnological Letters, Volume: 22 Issue: 2 Pages: 12347-12351, WOS:000403059300004.

33.COCULESCU, B.I., DINCA, G.V., MANOLE, G., PURCAREA, V.L., OPROIU, A.M., STOCHECI, C.M., Serum Concentration of hSCRP Possible Marker for Therapy Evaluation in Left Ventricular Dysfunction with Preserved Ejection Fraction, Rev. Chim. (Bucharest), 69, no. 10, 2018, p. 2885-2990, WOS:000451925300058.

34.SAJ IN, M; LUCHIAN, MC; PRISACARU, AH; DUMITRU, A; PATRASCU, OM; COSTACHE, D; DUMITRESCU, D; OPROIU, AM; SIMIONESCU, O; COSTACHE, M; Trichilemmal carcinoma - a rare cutaneous malignancy: report of two cases, Romanian J ournal of Morphology And Embryology, Volume: 55, Issue: 2, Pages: 687-691, Supplement: S, Published: 2014, WOS:000342868500027.

$\overline{\text { Manuscript received:22.07.2018 }}$ 